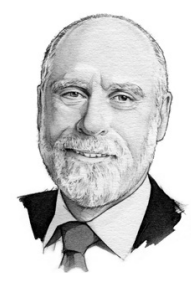

\title{
What Does a Static, Sustainable Economy Look Like?
}

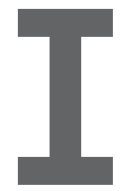

AM NOT AN economist. Come to think of it, I am not a lawyer either. But I would like to speculate a bit about what a static, sustainable economy might look like-or, at least, what conditions might have to be satisfied for such an economy to be realistic. On the presumption our present economy is heavily rooted in singleuse packaging, replace not repair, and growing populations to drive markets, we might conclude our consumption of non-renewable resources will be decreasingly sustainable. It is already apparent the most "advanced" economies are consuming resources far above their nominal share based on population. For a long time, a growing population assured increased consumption and thus an increasing GDP. I will set aside a rant about the inequality and inequity of income and wealth distribution as this is not germane to the more central question whether a static economy is sustainable or even desirable.

On the presumption the consumption of non-renewable resources is not sustainable, we might ask - as I have in previous columns - whether repairability and longevity of products and services might become increasingly important. Software may have a role to play here. The Tesla electric vehicle is a useful example. It increases its functionality and utility through new software-based capabilities. This extends the useful life of the vehicle.

Design for repairability and circular recycling strike me as elements of a sustainable but otherwise largely static economy. Innovation will still be important. As we exhaust some resources, we will need replacements.
Consider our reliance on fossil fuels, rare earths needed in electronics, raw materials needed for steel and concrete, and fresh water. As these resources diminish, research and innovation will be needed to compensate for their scarcity.

How will our profession-computer science-contribute to such a situation? First, computers and their software are becoming more critical to successful research in most fields. "Computational-X" for many values of " $\mathrm{X}$ " is heard more often in halls of academe and industry. So is machine learning for many applications, although it is not the panacea that some enthusiasts might lead people to think. Our ability to accumulate scientific data and make it more usefully relevant is improving and that will contribute to the discovery of solutions to resource scarcity and substitution. We should not forget the potential for increasing optimality in manufacturing and the associated supply chains. Someday, quantum computing may supply near real-time optimal solutions to scheduling, resource allocation, and other similar and potentially large-scale problems.

A key question is whether a nongrowing economy is feasible and habitable. For centuries the notion of "a growing business" had high value as an objective. A growing population contributed to that growth with its implicit increase in consumption. There is evidence, however, that this dynamic is changing. With time, we are seeing birth rates declining worldwide as non-agricultural economies demand less manual work, much of which is now done with machines. Robotics may also contribute to the reduction in demand for manual labor. It is certainly possible to imagine a static population with increasing consumption and demand satisfied by automation. But machines consume resources too for their manufacture and operation so that, too, may reach some limits.

The questions in my mind remain: Is a static economy feasible? Desirable? Habitable? Much deeper analysis is needed. One also wonders what the transition to such an economy would look like. I wonder the same for the transition from fossil fuel to electricity for vehicle propulsion. At some point you won't have enough fuel left in the tank to get to the nearest gas station for a refill. How will that process unfold and does it teach us anything about other scenarios in which what was once a vital resource is gone. Wood burning was replaced with alternative fuels-gas, coal, electricity-for cooking. All of those means were and still are concurrently in use although wood and coal are out in the long tail at this point with some exceptions in places where alternatives are too expensive to supply. At least wood is renewable, but excessive use can lead to disaster as seen in Haiti and in examples from Jared Diamond's book Collapse. ${ }^{\mathrm{a}}$

It remains for us to explore these potential transitions out of concern for resource scarcity, hazards of global warming, and the evident slowing of human population growth. I look forward to an ensuing discussion!

a J. Diamond. Collapse. Viking Press, 2004.

Vinton G. Cerf is vice president and Chief Internet Evangelist at Google. He served as ACM president from 2012-2014.

Copyright held by author/owner. 